\title{
Determinants of The Medium of Payment in Corporate Acquisitions
}

Dr. Gregory M. Noronha, Finance, Old Dominion University

Dr. Nilanjan Sen, Finance Arizona State University West

Dr. David M. Smith, Finance, University at Albany, SUNY

\begin{abstract}
This study identifies factors that may be correlated with the bidder's choice between offering cash versus stock in a corporate takeover. Results of a logistic regression analysis are generally consistent with information models involving the choice of payment type, as well as hypotheses related to the target's tax status. Support for Jensen's (1986) free cash flow hypothesis also is found.
\end{abstract}

\section{Introduction}

Recent research has focused on the importance of the bidder's method of payment for acquisitions. It is well known that returns to acquiring firms in tender offers, with cash as the usual method of payment, generally exceed those in mergers, which are typically common stock exchange offers. An association has also been documented between the medium of payment itself and shareholder returns.(1) Theoretical work suggests that the medium of payment contributes to the likelihood that other firms will enter the bidding.(2) In light of the importance of this choice that the bidder must make, it is surprising that very little empirical work to date evaluates factors that may influence the decision. The present research seeks to fill this void in the literature.

A number of studies have examined the effect the medium of payment has on stock returns of the parties to a merger or acquisition. Travlos (1987) reports that the payment method partially explains returns to the acquiring firm at the announcement of a takeover bid. Stockholders of pure stock exchange bidding firms experience statistically significant losses, while those of cash bidders earn normal returns around event dates. Examining the announcement period abnormal returns to target firms, Huang and Walkling (1987) find a relationship between the return and forms of payment, degree of resistance by target management, as well as the type of offer. Targets' abnormal returns are significantly higher for a) tender offers as opposed to mergers and b) cash offers relative to stock exchange acquisitions. After controlling for the form of payment and resistance effects, Huang and Walkling report that the returns to mergers and tender offers are not significant- ly different. Thus, higher returns reported for tender offers can be primarily attributed to the choice of payment method and the degree of resistance by the target.

Carleton, Guilkey, Harris, and Stewart (1983) model the bidder's medium of exchange decision as a function of target firm characteristics. They use data from 1976-77 and provide early empirical evidence on the determinants of payment medium. The likelihood of a stock takeover is found to be positively associated with the dividend payout ratio of target firms. The authors are unable to explain the result, as it runs counter to predictions of their tax-related hypothesis. The acquired firm's market-to-book ratio is positively related to the probability of a stock takeover. The sale of a stock that is richly valued relative to a firm's underlying assets can subject a target's stockholders to large tax liabilities. In such cases, a stock takeover may be preferred to one involving cash. Secondly, a low market-to-book ratio may reflect entrenched managers who can be effectively dislodged only through a cash tender offer.

The issue of payment medium has been analyzed theoretically in the context of the asymmetric information literature. In Hansen's (1987) model, a "lemons" problem(3) presents itself with cash offers, when the target firm knows its own value better than the bidder does. Only when the cash offer exceeds the firm's intrinsic value will the target shareholders agree to the offer. Hansen argues that, in light of this adverse selection, the bidder "must generally base its optimal offer not on unconditional expected value [of the target], 
but on expected value conditional on the offer being accepted."(4) Based on its private information, target management may not accept such an offer. To prevent the transaction's failure, the acquirer will prefer to offer stock, which has desirable contingent pricing characteristics. If the acquiring firm has proprietary information regarding its own value it creates an adverse selection problem on both sides (a 'double lemons' problem). However, the bidder is not likely to offer stock if the target severely undervalues the bidder's assets.

Tax considerations also play a large role in payment medium determination, according to the model of Brown and Ryngaert (1991).(5) Generally, stock offers have more favorable tax consequences. However, consistent with extant information models, Brown and Ryngaert predict that cash offers will be more likely for firms that seek to avoid issuing undervalued stock. Nonetheless, cash payments result in a significant tax liability for target shareholders, and building this cost into the offer causes such transactions to be expensive for bidders. To qualify as a nontaxable merger, the terms must involve stock as at least 50 percent of the purchase price. Thus, the interplay between information and tax factors may have a significant influence on the bidder's choice of payment medium.

This paper examines a set of explanatory factors consistent with the predictions of recent literature, and is organized as follows. Section II discusses the hypotheses for the study. Section III presents the methodology. Section IV describes the data used in the study. Section V gives the results of the study. Section VI concludes the paper with a summary and interpretation of the findings.

\section{Testable Hypotheses}

Explanatory variables for the medium of exchange model in this paper are derived from the extant literature. The motivation for each variable is discussed below.

\section{A. Free Cash Flow}

In Jensen's (1986) paper, "free" cash flow is defined as the cash in excess of the required funding for all of the firm's positive net present values projects. Shareholders prefer that managers pay out this excess cash rather than wasting it on inferior investments. Frequently, managers have an incentive to retain excess cash, possibly increasing firm size beyond the optimal level. Executive compensation is often tied to sales rather than profit, creating incentives for growth. Finally, firms reward middle managers through promotions rather than annual bonuses, which further creates a bias toward growth to generate new positions. In this framework, takeovers are both "evidence of the conflict between shareholders and managers and a solution to the problem."(6) The free cash flow hypothesis suggests that bidders with high free cash flow will be predisposed toward acquisitions financed with cash rather than by stock exchange.

Firms with large amounts of liquidity and few internal growth opportunities are considered to have high free cash flow. Accordingly, firms' undistributed cash flow is used as a proxy for free cash flow after controlling for growth opportunities. As an allowance for variability in liquidity needs across industries, the factor (LIQUIDITY) is expressed as the difference between the firm's undistributed cash flow and the mean value for the industry.(7) Following Lehn and Poulsen (1989), a firm's LIQUIDITY is measured as CF/EQ, where CF = INC - TAXEXP - INTEXP - PFDDIV - COMDIV. The variable INC represents operating income before depreciation, TAXEXP is total non-deferred income taxes, INTEXP is gross interest expense, PFDDIV is total dividend payments to preferred stockholders, COMDIV is total common stock dividends, and EQ is the market value of common equity. All variables are obtained as of the end of the fiscal year immediately preceding the year of the acquisition.

The variable GROWTH recognizes that only after controlling for firm growth can undistributed cash flow be treated as a proxy for free cash flow. In this study, the magnitude of future growth opportunities is assumed to be directly related to the firm's recent growth performance. GROWTH is measured as the three-year average increase in the book value of the bidder's assets, less that of its industry. After controlling for growth in this manner, the probability of a cash transaction is expected to be positively associated with the LIQUIDITY variable.

\section{B. Tax Attributes}

The attractiveness of a target firm is increased if it possesses accumulated tax losses and tax credits with which to shelter the acquirer's earnings. For the acquiring firm to be able to inherit desirable tax attributes requires "continuity of interest."(8) From a legal standpoint, two conditions must be met. The first is investor continuity. A majority of the target company's shares must be acquired in exchange for the stock of the acquiring firm. The target shareholders will then have an ownership interest in the merged firm. Second, continuity of target operations must be assured. The acquisition should have legitimate business purposes, as evidenced by the post merger continuation of the target's business. If these conditions are established, a merger becomes a tax-free reorganization in which the target shareholders' capital gains or losses can be deferred and the target's tax attributes inherited. 
U.S. tax laws permit net operating losses to be carried back three years and forward fifteen years. The present value of this carryover is small unless a firm is sufficiently profitable before or after the losses. However, the value of these tax features is increased when the losses are transferred to an acquiring firm with high pretax earnings. The tax variable (TAX) used in the medium of payment model is the total tax carryovers of the target firm, scaled by the net income of the acquiring firm.

Targets with high values for TAX will be prized for their ability to decrease a bidder's taxable income. However, the benefit is unobtainable unless the bidder's offer contains stock in an amount sufficient to meet continuity-of-interest requirements. Thus, a positive relationship is expected between the TAX factor and the probability of a stock takeover.

\section{Information Effects}

In the Myers and Majluf (1984) asymmetric information framework, managers acting in the interest of existing shareholders would prefer to make a cash offer when their firm is undervalued, while a common stock exchange is used in cases of overvaluation. The market participants thus interpret cash offers as good news and exchange offers as bad news about the true value of the firm. Consequently, any stock price change during an acquisition announcement reflects the information effects of the method of financing. It is hypothesized that bidders with higher information asymmetry regarding their value will finance acquisitions with cash in order to avoid the price decline that usually accompanies new stock issuances.(9) Following Booth and Smith (1986), the variance of the market model residual for the bidder's common stock, RESVARb, is used as a proxy for information asymmetry. It is computed using a pooled, 250-day estimation period, from days -150 to -25 and +25 to +150 relative to the first public takeover announcement involving the target. The factor is expected to be positively associated with the probability of a cash bid.

Models of bargaining under asymmetric information also yield several testable implications. For example, Hansen (1987) argues that the possession of proprietary information by the target leads to a "lemons" problem. The target will agree to sell only when its value is less than the offer being made. The bidder's offer, which is based on the expected value of the target conditional on the offer's acceptance, may not always be acceptable to the target. Consequently, to avoid this "thinning of markets" the acquirer will consider offering shares of stock, which have contingent pricing effects. At the same cost to the acquirer as a cash offer, a stock bid might induce the target to accept. However, the possibility of the bidder having proprietary information may lead the target to undervalue the bidder's stock, reducing the likelihood of a stock offer. Equilibrium may be reached where the target treats the medium of exchange and the merger exchange ratio as a signal of the bidding firm's value while the bidder chooses the medium of exchange and offering size "to sustain the target's beliefs."(10) In this framework, the probability of a stock trade is inversely related to the bidder's size relative to the target's. This is because stock's contingent pricing characteristics depend upon the target's asset size being significant relative to the bidder's. Further, when debt is incorporated into the model, the probability of a stock trade rises with the acquirer's debt, and declines with the target's debt level. Again, the contingent pricing features of the stock are more pronounced the larger the equity of the target relative to the equity of the acquirer. Accordingly, three factors are used to test Hansen's model. DEBTt is the target's debt scaled by its total assets, and DEBTb is measured identically for the bidder. The relative sizes of the firms are given by the factor ASSETb/t, which is computed as the bidder's total assets divided by the target's.

\section{Regulatory Delays}

The form of payment will influence bidding strategy if it affects the anticipated net present value of an acquisition. Payment method can affect the net present value through interrelations with either takeover costs or the probability of success, or both. Wansley, Lane and Yang (1987) note that in stock offers a bidding firm must obtain approval from the Securities and Exchange Commission before target stockholders begin to tender their shares. This process can take as long as several months. In contrast, a bidder paying cash could start to acquire target shares within a few days of the initial announcement. Transaction speed can determine the success of a hostile takeover, since the longer processing time for stock offers gives the target's management a greater opportunity to mount a defense. Moreover, potential rival bidders might have time to assemble competing offers. Further, the regulatory delay accompanying a hostile, stock-exchange takeover can also allow the target firm's management to reveal selective information about its value to preferred (rival) bidders. This information may result in an upward revision of cash flow estimates, a reduction in uncertainty faced by such favored bidders, or both. As a consequence, favored bidders could offer higher premiums. Hostile stock offers may then have a smaller probability of success than those made with cash. A dummy variable reflecting whether a takeover should be classified as "hostile" takes on a value of "1" if the target firm's board or management made any public statements of opposition to the bidder's offer. It is expected that this factor (HOSTILE) will be positively related to the probability of a cash offer. 


\section{Methodology}

The empirical methodology involves the use of a logistic regression model with the Gauss-Newton method of non-linear estimation. A state-based sampling procedure is used to improve the efficiency of the parameter estimates. Biases associated with such a sampling procedure are avoided by using a conditional maximum likelihood estimation algorithm, following Palepu (1986).

There is a valid econometric justification for preferring a state-based sample over a random sample in estimating the acquisition choice mechanism. The number of stock exchange offers is much smaller than the number of cash transactions. If a random sample were drawn from the population of all takeovers, a majority of the transactions would be for cash. A comparatively small proportion of the sample would involve stock exchanges. The information content of such samples for model estimation is small. Coslett (1981) shows that when the dependent variables are discrete, the optimum efficiency is derived from having (or creating) subsamples that are roughly equally represented in the total sample. Hence, in the present study the stock offers are matched up with an equal number of randomly selected cash offers.(11)

The efficiency gain in state-based samples is conditional on the use of an estimation technique that recognizes the nature of the sampling procedure. Manski and Lerman (1977) show that with state-based sampling, the use of estimation methods which assume random sampling leads to inconsistent and asymptotically biased estimates of model parameters. The use of the simple maximum likelihood procedure (which assumes random sampling) consists of maximizing the sample likelihood function. In a state-based sample, the probability (p) of an event being a cash offer in the population is not the same as the probability (p') of an event being a cash offer in the sample. Since the sample likelihood is formed using p', the maximization of the sample likelihood yields inconsistent and asymptotically biased estimates.

The aforementioned biases can be avoided, however, by recognizing the nature of samples in the estimation procedure. Manski and McFadden (1981) suggest the use of a conditional maximum likelihood estimator in which the conditional probability that the acquisition is cash-financed, given that it is included in the sample, is used to compute the likelihood function.

\section{Data}

The CRSP tapes were searched for delistments from the New York and American Stock Exchanges between 1980 and 1988. The Wall Street Journal Index was used to determine if the transaction was a successful merger or tender offer and if it involved cash or stock. A further screen was established for corporate financial data availability on Compustat, leaving 121 firms involved in completed cash transactions and 37 in successful stock bids. For methodological reasons mentioned earlier, thirty-seven acquisitions (representing 31 percent of the total firms available) were randomly selected from the cash transaction group in order to equalize the two subsample sizes.

Table 1

Chronological Distribution of Cash and Stock Takeover Samples

\begin{tabular}{ccc}
\hline Year & Cash & Stock \\
\hline 1980 & 10 & 2 \\
1981 & 0 & 0 \\
1982 & 6 & 2 \\
1983 & 6 & 2 \\
1984 & 1 & 3 \\
1985 & 3 & 4 \\
1986 & 7 & 7 \\
1987 & 3 & 7 \\
1988 & 1 & 10 \\
Total & 37 & 37 \\
& & \\
\hline
\end{tabular}

Table 1 shows the distribution of the subsamples over time. The randomly selected cash offers are distributed across the years in the same general proportions as they occurred in the larger sample from which they were drawn. The use of stock as the medium of exchange appears to have increased over time, while a decrease 
can be seen in the relative frequency of cash offers.

\section{Results}

Comparisons of means for the independent variables are given in Table 2. For most of the explanatory factors, the differences are in the expected direction, though they are generally statistically insignificant. One exception is the HOSTILE dummy variable. Target management opposition is much more prevalent with cash takeovers than with stock transactions. The free cash flow control variable, GROWTH, is also significantly higher for cash bidders than for acquirers in stock transactions. Just on the margin of statistical significance is the relative size variable, ASSETb/t, suggesting that size differences between participants in cash transactions are greater than the differences for parties in stock exchanges.

The inferential value of univariate comparisons is clearly limited, as numerous factors may be acting in

Table 2

Univariate Analysis of Explanatory Variables for Cash vs. Stock Transactions

\begin{tabular}{|c|c|c|c|c|}
\hline \multirow[b]{2}{*}{ Variable $\mathbf{a}^{\mathbf{a}}$} & \multicolumn{2}{|c|}{ Mean Value } & \multicolumn{2}{|c|}{ Differences } \\
\hline & $\begin{array}{c}\text { Cash } \\
\text { Transaction }\end{array}$ & $\begin{array}{c}\text { Stock } \\
\text { Transaction }\end{array}$ & $\mathrm{t}$ & $\begin{array}{l}\text { Prob } \\
\text { Value }\end{array}$ \\
\hline LIQUIDITY & $\begin{array}{c}0.10^{\mathbf{b}} \\
(0.24)\end{array}$ & $\begin{array}{c}0.08 \\
(0.16)\end{array}$ & 0.36 & 0.71 \\
\hline$T A X$ & $\begin{array}{l}-0.05 \\
(2.36)\end{array}$ & $\begin{array}{c}0.58 \\
(3.37)\end{array}$ & -0.94 & 0.34 \\
\hline$R_{E S V A R_{b}}$ & $\begin{array}{c}0.43 \\
(0.46)\end{array}$ & $\begin{array}{c}0.37 \\
(0.34)\end{array}$ & 0.64 & 0.51 \\
\hline$D E B T_{t}$ & $\begin{array}{c}0.25 \\
(0.18)\end{array}$ & $\begin{array}{c}0.24 \\
(0.14)\end{array}$ & 0.41 & 0.68 \\
\hline$D E B T_{b}$ & $\begin{array}{c}0.23 \\
(0.18)\end{array}$ & $\begin{array}{c}0.22 \\
(0.11)\end{array}$ & 0.03 & 0.96 \\
\hline$A S S E T_{b / t}$ & $\begin{array}{c}30.27 \\
(50.61)\end{array}$ & $\begin{array}{c}15.64 \\
(27.66)\end{array}$ & 1.54 & 0.12 \\
\hline HOSTILE & $\begin{array}{c}0.21 \\
(0.41)\end{array}$ & $\begin{array}{c}0.02 \\
(0.16)\end{array}$ & 2.56 & 0.01 \\
\hline GROWTH & $\begin{array}{c}0.12 \\
(0.38)\end{array}$ & $\begin{array}{l}-0.02 \\
(0.29)\end{array}$ & 1.87 & 0.06 \\
\hline
\end{tabular}

a LIQUIDITY is CF/EQ, where CF = INC - TAXEXP - INTEXP - PFDDIV - COMDIV. INC represents operating income before depreciation, TAXEXP is total non-deferred income taxes, INTEXP is gross interest expense, PFDDIV is total dividend payments to preferred stockholders, COMDIV is total common stock dividends, and EQ is the market value of common equity. All variables are obtained as of the end of the fiscal year immediately preceding the year of the acquisition. TAX is the total tax carryovers of the target firm, scaled by the net income of the acquiring firm. RESVAR $b$ is the the variance of the market model residual for the bidder's common stock, computed using a pooled, 250-day estimation period, from days -150 to -25 and +25 to +150 relative to the first public takeover announcement involving the target. $D E B T_{t}$ is the target's debt scaled by its total assets, and $D E B T_{b}$ is measured identically for the bidder. $A S S E T_{b / t}$ is the bidder's total book assets divided by the target's. HOSTILE is a dummy variable, taking on a value of " 1 " if the target firm's board or management made any public statements of opposition to the bidder's offer, and " 0 " otherwise. GROWTH is measured as the three-year average increase in the book value of the bidder's assets, less that of its industry.

b Standard deviation in parentheses. 
concert to determine the chosen medium of payment. Multivariate logistic regression results are reported in Table 3. Multicollinearity diagnostics indicate very low correlations among the independent variables. Seven of the explanatory factors have regression coefficients with the expected signs, and five are statistically significant. Elasticity coefficients show the percentage change in the likelihood of a cash takeover for a one percent change in each explanatory factor. The elasticities are computed at each regressor's mean value, and help to evaluate

Table 3

Parameter Estimates for Logistic Regression of Medium of Payment Type on Explanatory Variables

\begin{tabular}{lccc}
\hline Variable $^{\mathbf{a}}$ & $\begin{array}{c}\text { Parameter } \\
\text { Estimate }\end{array}$ & t-Statistic & $\begin{array}{c}\text { Elasticity } \\
\text { Coefficient }\end{array}$ \\
\hline INTERCEPT & -0.2035 & -0.40 & $\mathrm{NA}^{\mathbf{b}}$ \\
LIQUIDITY & 3.1319 & $2.05^{* *}$ & 0.1237 \\
$T_{A X}$ & -0.2871 & $-1.72^{*}$ & -0.0307 \\
RESVAR $_{b}$ & 4.4443 & 0.97 & 0.0734 \\
DEBT $_{t}$ & 3.6046 & $2.53^{* *}$ & 0.3626 \\
DEBT $_{b}$ & -7.1662 & $-2.61^{* *}$ & -0.2604 \\
$A S S E T_{b / t}$ & 0.0075 & 1.26 & 0.0697 \\
HOSTILE $_{\text {GROWTH }}$ & 10.7297 & 0.31 & 0.5279 \\
& 3.5183 & $2.77^{* * *}$ & 0.0701
\end{tabular}

Model Statistics:

Likelihood ratio statistic

Likelihood ratio index

* Statistically significant at the .10 level, two-tailed test.

** Statistically significant at the .05 level, two-tailed test.

*** Statistically significant at the .01 level, two-tailed test.

a The dependent variable takes on a value of 1 if the medium of payment is cash, and 0 if it is stock. LIQUIDITY is CF/EQ, where CF = INC - TAXEXP - INTEXP - PFDDIV - COMDIV. INC represents operating income before depreciation, TAXEXP is total non-deferred income taxes, INTEXP is gross interest expense, PFDDIV is total dividend payments to preferred stockholders, COMDIV is total common stock dividends, and EQ is the market value of common equity. All variables are obtained as of the end of the fiscal year immediately preceding the year of the acquisition. TAX is the total tax carryovers of the target firm, scaled by the net income of the acquiring firm. RESVAR $b$ is the the variance of the market model residual for the bidder's common stock, computed using a pooled, 250-day estimation period, from days -150 to -25 and +25 to +150 relative to the first public takeover announcement involving the target. $D E B T_{t}$ is the target's debt scaled by its total assets, and $D E B T_{b}$ is measured identically for the bidder. $A S S E T_{b / t}$ is the bidder's total book assets divided by the target's. HOSTILE is a dummy variable, taking on a value of " 1 " if the target firm's board or management made any public statements of opposition to the bidder's offer, and " 0 " otherwise. GROWTH is measured as the three-year average increase in the book value of the bidder's assets, less that of its industry.

b NA: not applicable. Elasticity coefficients are computed for each factor at its mean value.

c A measure of the explanatory power of the model, similar to $\mathrm{R}^{2}$. 
the economic significance of the relationship. The model's likelihood ratio statistic of 31.75 indicates that the selected group of factors substantially explains the bidder's choice of payment method.

A positive and statistically significant coefficient is found for LIQUIDITY, the free cash flow variable. Firms with high levels of free cash flow thus prefer to make acquisitions with cash. This finding is supportive of Jensen's (1986) hypothesis, which suggests that cash-related takeovers are a partial solution to the agency cost of excess free cash flow.(12) The TAX variable is positively related to the likelihood of a stock bid. This is consistent with bidders attempting to capture the target's tax benefits that stem from previous operating losses. The larger are such losses relative to the bidder's net income, the greater is the tendency for the acquirer to make a stock offer. Under the "continuity of interest" doctrine stock must be a significant part of the transaction, so the result is as expected.

An empirical proxy used for the information asymmetry hypothesis is the bidding firm's residual variance computed from the market model. The level of information asymmetry is expected to be positively related to the probability of a cash bid, as bidders are reluctant to use undervalued stock as scrip for takeovers. Though the coefficient of RESVARb has the predicted positive sign, it is statistically insignificant. Three variables are related to predictions of Hansen (1987), and two of them have significant coefficients with the hypothesized signs. The probability of a cash transaction is positively related to the target's debt-to-asset ratio, and negatively to the bidder's leverage. A ratio of the two parties' assets, ASSETb/t, is found to be insignificant, though with the predicted positive coefficient. Unfortunately, the book value of assets is only an approximation of the assets' true value. As Hansen points out, a firm's information structure tends to change with asset size. In general, more information is publicly available for larger firms, thus increasing the likelihood of a stock rather than cash takeover.

The coefficient for the HOSTILE dummy, which indicates whether there was resistance to the offer by target firm management, is positive, though not significant. It was postulated that a hostile takeover is more likely to involve cash than stock. This follows from the fact that hostile cash takeovers can be effected more quickly than hostile stock acquisitions, as regulatory delays tend to occur more frequently with the latter variety. In other words, it is likely that the medium of payment is determined, in part, with the expected reaction of target management in mind.

Finally, the free cash flow "control" variable, GROWTH, is found to have a significant positive correlation with the probability of a cash bid. The positive sign and statistical significance of this control factor are unexpected. An explanation for why higher growth bidders apparently gravitate toward cash as a medium of payment remains elusive.(13)

\section{Conclusions}

This study is an empirical investigation of the factors related to the bidding firm's choice between cash or stock in a corporate takeover. Explanatory variables are derived from recent literature in the corporate control area. A state-based sampling procedure is used to address potential biases associated with violations of the usual random sampling assumption. Following Palepu (1986), conditional maximum likelihood parameter estimates are generated for the logistic regression specification.

The findings support Jensen's (1986) free cash flow hypothesis; the bidder's free cash flow level is found to be directly related to the probability of a cash takeover. A tax-related hypothesis also is confirmed, as the bidder's propensity to make a stock bid is positively related to the level of accumulated tax credits carried by the target firm. Interestingly, the nature of the acquisition (hostile/friendly) is apparently not associated with the medium of payment decision, though in practice the target's receptiveness is often not known until after the characteristics of the bid are known. The predictions of Hansen's (1987) model are largely borne out, with all three associated factors having the expected signs and two showing statistical significance. The coefficient for one information factor (RESVARb), a proxy for the degree of asymmetry regarding the target's value, is statistically insignificant. However, as Hansen hypothesizes, the probability of a stock takeover is negatively related to the target's debt-to-asset ratio, and positively related to the bidder's leverage. In total, the data generally support the predictions of free cash flow, tax-related, and information models of the medium of exchange decision.

\section{Suggestions For Further Research}

The sample for this study includes takeovers involving only cash or stock. In a large minority of cases, a mixture of cash and stock (and sometimes debt) is used as scrip by acquirers. Further research is needed to deal with this reality, perhaps treating the medium of payment as a continuous variable. Another possible extension of this work is to employ logistic regression methodology to examine additional aspects of the takeover process, including the propensity for multiple bidders to emerge in certain situations.

The comments of Hany A. Shawky, David C. Smith, and 
two anonymous referees are gratefully acknowledged.

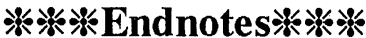

1. Travlos (1987) and Huang and Walkling (1987) find that both merger parties tend to fare better in cash transactions than with stock exchange offers.

2. Fishman (1989) develops a model of the medium of exchange in an environment where multiple bidders may be present. In his analysis, the target and bidder each possesses private information about the acquisition's profitability. Competition is found to be more apt to arise among bidders in the case of a stock offer than with a cash offer (p. 42).

3. For a complete discussion of the problem, see Akerlof (1970).

4. See Hansen (1987, p. 76).

5. Hayn (1989) discusses the affect of tax considerations on stockholder returns in acquisitions. Gains to the parties in takeovers are found to be strongly associated with two attributes, tax loss carryforwards and expiring tax credits, and the step-up of the acquired firm's basis.

6. See Jensen (1986), page 328.

7. The "industry" is defined as all firms with the same four-digit SIC code.

8. See Weston, Chung, and Hoag (1990, p. 209), for a more detailed description of the requirements for continuity of interest.

9. Masulis and Korwar (1986), Asquith and Mullins (1986), Mikkelson and Partch (1986), and Kalay and Shimrat (1987) give extensive analyses of the (negative) impact of equity offerings.

10. Hansen's words (p. 77).

11. For example, when developing samples for a bankruptcy prediction model, the number of non-bankrupt firms in the population at large far exceeds the number of bankrupt ones. Once the "bankrupt" subsample is established, the "non-bankrupt" data can be randomly chosen from the total group of such firms. The selection proceeds until the two subsample sizes are equated. This state-based procedure, according to Coslett, represents a nearly optimum design.

12. It is possible that a firm with high LIQUIDITY could make a negative-NPV acquisition using cash, thus reducing free cash flow but negatively affecting the stock price. Thus, a cash acquisition may not always represent an agency cost-reducing strategy. Still,. the GROWTH variable is designed to control for situations in which business conditions currently necessitate new investments.

13. Consistent with Fishman's (1989) model, the present analysis was performed with a factor measuring the degree of competition in each takeover, though the variable was found to contribute insignificantly to the model's explanatory power.

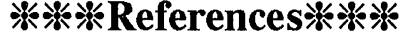

1. Akerlof, George A., "The Market for 'Lemons': Qualitative Uncertainty and the Market Mechanism," Quarterly Journal of Economics, Vol. 89, pp. 488-500, 1970.

2. Asquith, Paul, and Mullins, David W., "Equity Issues and Offering Dilution," Journal of Financial Economics, Vol. 15, pp. 61-89, 1986.

3. Booth, James R., and Richard L. Smith, "Capital Raising, Underwriting and the Certification Hypothesis," Journal of Financial Economics, Vol. 15, pp. 261-281, 1986.

4. Brown, David T., and Michael D. Ryngaert, "The Mode of Acquisition in Takeovers: Taxes and Asymmetric Information," Journal of Finance, Vol. 46, pp. 653-659, 1991.

5. Carleton, Willard T., David K. Guilkey, Robert S. Harris, and John F. Stewart, "An Empirical Analysis of the Role of the Medium of Exchange in Mergers," Journal of Finance, Vol. 38, pp. 813-826, 1983.

6. Coslett, S. R., "Efficient Estimation of Discrete Choice Models," in C. F. Manski and D. McFadden, eds., Structural Analysis of Discrete Data with Econometric Applications, (MIT Press, Cambridge, Mass.), 1981.

7. Fishman, Michael J., "Preemptive Bidding and the Role of the Medium of Exchange in Acquisitions," Journal of Finance, Vol. 44, pp. 41-57, 1989.

8. Hansen, Robert G., "A Theory for the Choice of Exchange Medium in Mergers and Acquisitions," Journal of Business, · Vol. 60, pp. 75-96, 1987.

9. Hayn, Carla, "Tax Attributes as Determinants of Shareholder Gains in Corporate Acquisitions," Journal of Financial Economics, Vol. 23 (June), pp. 121-153, 1989.

10. Huang, Yen-Sheng, and Ralph A. Walking, "Target Abnormal Returns Associated with Acquisition Announcements: Payment, Acquisition Form, and Managerial Resistance," Journal of Financial Economics, Vol. 19 (June), pp. 329-350, 1987.

11. Jensen, Michael C., "Agency Costs of Free Cash Flow, Corporate Finance, and Takeovers," American Economic Review, Vol. 76, pp. 323-339, 1986.

12. Jensen, Michael C., and Richard S. Ruback, "The Market for Corporate Control: The Scientific Evidence," Journal of Financial Economics, Vol. 11, pp. 5-50, 1983.

13. Kalay, Avner, and Shimrat, Adam, "Firm Value and Seasoned Equity Issues: Price Pressure, Wealth Redistribution, or Negative Information?," Journal of Financial Economics, Vol. 19, pp. 109-126, 1987.

14. Lehn, Kenneth, and Annette B. Poulsen, "Free Cash Flow and Stockholder Gains in Going Private Transactions," Journal of Finance, Vol. 44, pp. 771-787, 1989.

15. Manski, C. F., and S. R. Lerman, "The Estimation 
of Choice Probabilities from Choice Based Samples," Econometrica, pp. 45-8, 1977.

16. Manski, C. F., and D. McFadden, "Alternative Estimators and Sample Designs for Discrete Choice Analysis," in: C. F. Manski and D. McFadden, eds., Structural Analysis of Discrete Data with Econometric Applications (MIT Press, Cambridge, Mass.), 1981.

17. Masulis, Ronald W., and Ashok N. Korwar, "Seasoned Equity Offerings: An Empirical Investigation," Journal of Financial Economics, Vol. 15, pp. 91-118, 1986.

18. Mikkelson, Wayne H., and M. Megan Partch, "Valuation Effects of Security Offerings and the Issuance Process," Journal of Financial Economics, Vol. 15, pp. 31-60, 1986.

19. Myers, Stewart C., and Nicholas S. Majluf, "Corporate Financing and Investment Decisions When Firms Have Information That Investors Do Not Have," Journal of Financial Economics, Vol. 13, pp. 187-221, 1984.

20. Palepu, Krishna G., "Predicting Takeover Targets: A Methodological and Empirical Analysis," Journal of Accounting and Economics, Vol. 8, pp. 3-35, 1986.

21. Travlos, Nicholaos G., "Corporate Takeover Bids, Method of Payment, and Bidding Firms' Stock Returns," Journal of Finance, Vol. 42 (September), pp. 943-963, 1987.

22. Wansley, James W., William R. Lane, and Ho C. Yang, "Gains to Bidder Firms in Cash and Securities Transactions," Financial Review, Vol. 22, pp. 403-414, 1987.

23. Weston, J. Fred, Kwang S. Chung, and Susan E. Hoag, Mergers, Restructuring, and Corporate Control, Prentice-Hall: Englewood Cliffs, NJ, 1990. 